\title{
MANTLE HEAT FLOW
}

\author{
HENRY N. POLLACK and DAVID S. CHAPMAN ${ }^{1}$ \\ Department of Geology and Mineralogy, The University of Michigan, Ann Arbor, Mich. (USA)
}

Received July 19, 1976

Revised version received November 24,1976

\begin{abstract}
A map of the heat flux out of the earth's mantle has been prepared by subtracting the heat flow arising in the earth's crust from the surface heat flow. In continental areas the crustal contribution of the enriched zone is determined from the parameters of the linear heat flow-heat production relationship $q_{0}=q^{*}+b A_{0}$ in areas where such data exist. Where heat flow-heat production data are not available, a new empiricism relating reduced heat flow $q^{*}$ to the mean heat flow of a province $\bar{q}_{0}, q^{*} \cong 0.6 \bar{q}_{0}$, is used to estimate the reduced heat flow, and the depth parameter $b$ is assigned an average value of $8.5 \mathrm{~km}$. The oceanic crustal heat flow contribution includes both heat liberated by cooling, which is a function of the age of the ocean floor, and a small radiogenic component. A spherical harmonic analysis to degree 18 of the computed $5^{\circ} \times 5^{\circ}$ mantle heat flow values yields a mean of $48 \mathrm{~mW} \mathrm{~m}^{-2}$; the degree variance spectrum has prominent strength at degrees 1,4 and 5. Continent-ocean differences are more apparent in the mantle heat flow than in the surface heat flow. However, contrasting surface heat flow patterns within continents, such as in central and western Australia, which arise from different surficial radioactivity distributions, do not appear in the mantle heat flow. Mantle heat flow is positively correlated with the geopotential and negatively correlated with the topography of the earth. However, correlation of heat flow with a "normalized" topography, in which the base line elevation difference between oceans and continents is suppressed is significantly positive, in accordance with observation that ocean floor topography is thermally controlled.
\end{abstract}

\section{Introduction}

The heat conducted to the earth's surface from its interior averages about $60 \mathrm{~mW} \mathrm{~m}$, and most of the regional variation in heat flux lies within a factor of three about the mean. In the oceans the heat flow decreases with increasing age of the ocean floor, while on continents the mean heat flow in tectonic elements of different ages decreases with increasing age of the tectonic element. Within a given tectonic unit, the variation about the mean arises principally from regional variation in crustal radioactivity.

Although heat flow measurements still have not been made in large areas of some continents and in the high-latitude oceans, a reasonable global heat flow map has been developed [1] by using heat flow-tectonic age correlations to estimate heat flow where no

\footnotetext{
1 Present address: Department of Geology and Geophysics,
} University of Utah, Salt Lake City, Utah, U.S.A. observations exist, thereby supplementing the observed data set to yield a mean heat flow for each $5^{\circ} \times 5^{\circ}$ element of the globe. The global heat flow map which results from a 12 th degree spherical harmonic analysis of the full supplemented data set is shown in Fig. 1, and this map will probably be very similar to one arising from a data set comprised completely of observations.

With heat flow at the surface reasonably well known we now turn our attention to the heat flow at interior boundaries such as the crust-mantle boundary or the lithosphere-asthenosphere interface. Variation of hea1 flow with depth is implicit in all models of the earth in which rocks have radioactive heat production or are cooling by an outward heat loss. In continents, about 0.4 of the surface heat flow is radiogenically produced in the outer half of the crust. The oceanic crust on the other hand contributes relatively little radiogenic heat; rather a significant fraction of oceanic heat flow arises in the crust by virtue of its heat capa- 


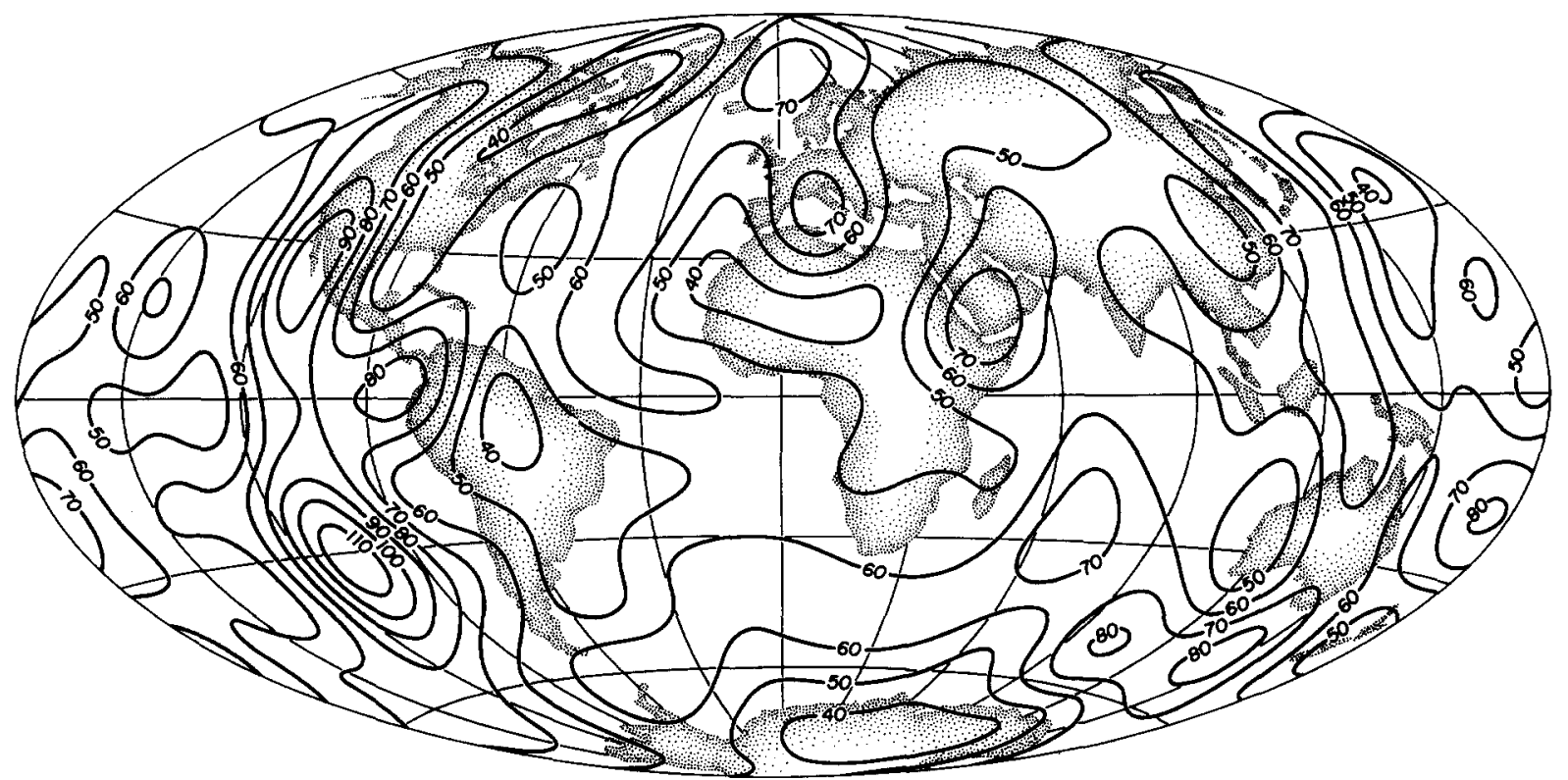

Fig. 1. Degree 12 spherical harmonic representation of surface heat flow. Contours in $\mathrm{mW} \mathrm{m}^{-2}$.

city; this heat is liberated as the oceanic lithosphere cools. A new data set of mantle heat flow values can be obtained by stripping these crustal contributions from the surface heat flow values. The procedures of heat flow stripping and the subsequent analysis of the mantle heat flow data set so derived comprise the body of this paper.

\section{Crustal contributions to surface heat flow}

\subsection{Continents}

The rocks of the continental crust are enriched in heat-producing radioactive isotopes of uranium, thorium and potassium. In fact the entire surface heat flow could arise within the crust if the surface concentrations of the principal heat-producing isotopes of $\mathrm{U}$, Th and $\mathrm{K}$ extended to a depth of about $35 \mathrm{~km}$. However, this is unlikely to be the case, as probable lower crustal and upper mantle rocks are observed to have lesser concentrations of these isotopes, and so heat production must decrease in some manner with depth. Some restrictions are placed on the vertical distribution of radiogenic heat sources by the empirical linear relationship between surface heat flow $q_{0}$ and surface heat production $A_{0}$. This relation, first reported for plutonic rocks by Birch et al. [2], now seems to be applicable in many non-plutonic settings as well. The relationship is expressed as $q_{0}$ $=q^{*}+b A_{0}$ where $q_{0}$ is the surface heat flow, $A_{0}$ is the heat production of the surface rocks, $q^{*}$ is the reduced heat flow (the heat flow intercept for zero heat production) and $b$ is a quantity with dimension of depth which characterizes the vertical source distribution. Several heat production distributions satisfy the above relationship $[2,3]$ although only the exponential source model of Lachenbruch [3] maintains the relationship through differential erosion. Field studies by Swanberg in the Idaho batholith [4] and by Hawkesworth in the eastern Alps [5], undertaken to determine the nature of the variation of heat production with depth, lend general support to the exponential source model. The linear heat flow heat production relationship and the exponential enrichment model offer a reasonable explanation, in terms of variations in shallow crustal radioactivity, for the variation of heat flow within a heat flow province.

The nature of heat production in the lower crust is less certain, but studies by Hyndman et al. [6], and Smithson and Decker [7] provide some guidance. 
Heat production clearly decreases with increasing metamorphic grade, although the actual values depend on whether the rocks are in hydrous or anhydrous facies. Reasonable values for heat production in the lower crust probably lie between 0.2 and $0.6 \mu \mathrm{W} \mathrm{m}^{-3}$.

In order to obtain mantle heat flow values for continental areas we utilize a generalized heat production model shown in Fig. 2. It consists of an enriched surface zone in which heat production decreases exponentially from a surface value $A_{0}$ until it reaches the lower crustal value of $A_{1}$, below which the heat production is constant. The depth at which the transition from the exponential to uniform distributions occurs depends on values of the parameters $A_{0}, b$, and $A_{1}$ and is given by $z=b \ln \left(A_{0} / A_{1}\right)$. In the steady state the surface heat flow $q_{0}$ is in equilibrium with the mantle flux $q_{\mathrm{m}}$ plus radiogenic heat from the crust. The mantle heat flow may be expressed as:

$q_{\mathrm{m}}=q_{0}-\left\{\left(A_{0}-A_{1}\right) b+A_{1}\left[z_{\mathrm{m}}-b \ln \left(A_{0} / A_{1}\right)\right]\right\}$

where $q_{0}$ is the surface heat flow, $b$ is the depth parameter (logarithmic decrement) for the exponen-

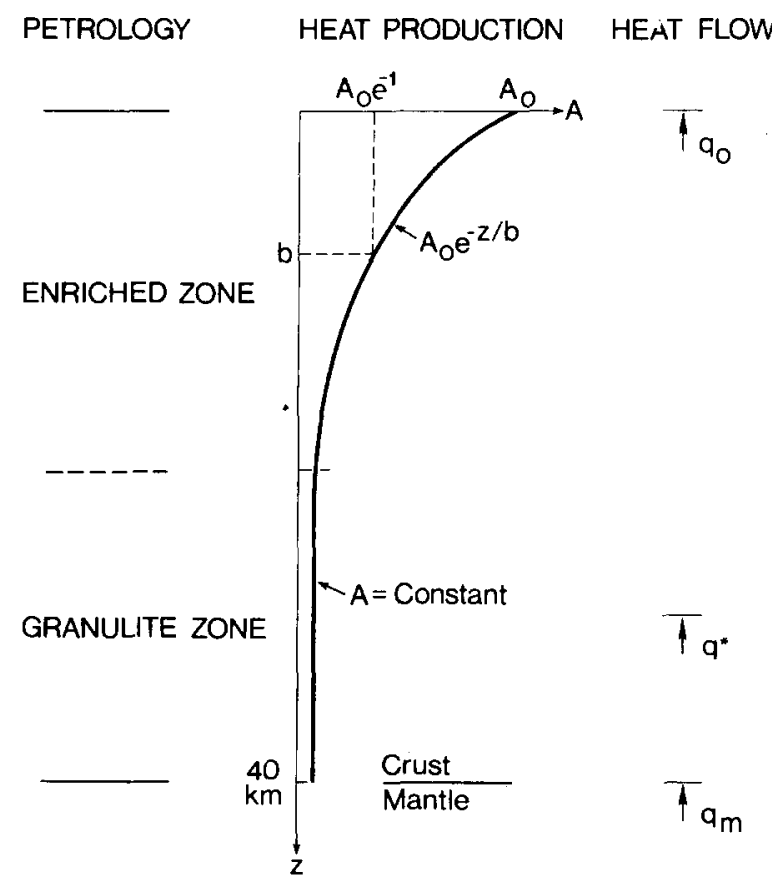

Fig. 2. Continental crust heat production and heat flow model. Symbols defined in text. tial source model, $z_{\mathrm{m}}$ is the depth to the mantle, $A_{0}$ is the surface heat production, and $A_{1}$ is the lower crust heat production. Ordinarily $q_{0}, A_{0}, q^{*}$ and $b$ are known only where heat flow-heat production studies have been carried out. However, we propose a new and simple empirical relationship between $q^{*}$ and $\bar{q}_{0}$, the mean heat flow within a province, which will enable reasonable estimates of all necessary parameters to be made from a knowledge of the mean heat flow of a province.

In Table 1 we have assembled much of the available data for heat flow provinces for which reduced heat flow has been estimated. The entries in Table 1 are of varying quality, ranging from tightly constrained values where least squares lines have been fitted to many heat flow-heat production pairs, to a few measurements with insufficient range for reliable estimates of $q^{*}$ and $b$ by line fitting. In the latter situation $b$ was assumed and a line passing through the cluster of points was used. The estimates of $\bar{q}_{0}$, the mean heat flow of a province, are given by the original authors, or have been extracted from graphs or calculated from data lists by us.

Provided the heat flow sites are representative of the province as a whole, one can show that $\bar{q}_{0}=q^{*}$ $+b \bar{A}_{0}$ where $\bar{A}_{0}$ is the mean heat generation of the province. Thus the mean heat flow of a province, like the local flux at individual sites, comprises contributions from within and below an enriched zone.

It is apparent from Table 1 that $b$ lies within a quite restricted range; $8.5 \pm 1.5 \mathrm{~km}$ encompasses most results. The effect that a $3-\mathrm{km}$ range in $b$ can have on the variation of $\bar{q}_{0}$ between provinces can be easily estimated. Assume that $q^{*}$ and the mean heat production are the same for two provinces, but that $b$ differs by the above indicated range of $3 \mathrm{~km}$. For a typical upper crustal heat production of $2.5 \mu \mathrm{W} \mathrm{m} \mathrm{m}^{-3}$ one would obtain a variation in $\bar{q}_{0}$ of only $7.5 \mathrm{~mW} \mathrm{~m}^{-2}$. As differences between provinces range up to several tens of $\mathrm{mW} \mathrm{m}^{-2}$, it is clear that the major element in the variation of mean heat flow from province to province must be variations in $\overline{A_{0}}$ and $q^{*}$, the mean heat production within and input from below the enriched surface zone, respectively.

We have plotted $q^{*}$ versus $\bar{q}_{0}$ (Fig. 3) for the regions and data shown in Table 1. A linear relationship emerges from which we tentatively establish a new empiricism relating reduced heat flow to mean surface 
TABLE 1

Mean heat flow, reduced heat flow, and characteristic depth of heat source distribution, for several heat flow provinces

\begin{tabular}{lllll}
\hline Province & $\begin{array}{l}\text { Mean heat flow } \\
\left(\mathrm{mW} \mathrm{m}^{-2}\right) \\
\pm \text { std. devia- } \\
\text { tion }\end{array}$ & $\begin{array}{l}\text { Reduced heat } \\
\text { flow }\left(\mathrm{mW} \mathrm{m}^{-2}\right) \\
\pm \text { uncertainty }\end{array}$ & $\begin{array}{l}\text { Characteristic } \\
\text { depth } b(\mathrm{~km})\end{array}$ & References \\
& & & & \\
\hline Basin and Range & $92 \pm 13$ & $59 \pm 8$ & 9.4 & {$[8,9,19]$} \\
Central Australia & $81 \pm 10$ & $27 \pm 6$ & 11.1 & {$[11,21]$} \\
Zambia & $67 \pm 7$ & $40 \pm 6$ & & {$[12]$} \\
Eastern U.S.A. & $57 \pm 17$ & $33 \pm 4$ & 7.5 & {$[8]$} \\
Canadian shield & $39 \pm 7$ & $28 \pm 6$ & 9.8 & {$[13]$} \\
Western Australia & $39 \pm 8$ & $27 \pm 8$ & 4.5 & {$[11,13,21]$} \\
Sierra Nevada & $39 \pm 12$ & $17 \pm 2$ & 10.1 & {$[9,10]$} \\
Baltic shield & $36 \pm 8$ & $22 \pm 6$ & 8.5 & {$[13]$} \\
Niger & $20 \pm 8$ & $11 \pm 8$ & 8 & {$[14]$} \\
\hline
\end{tabular}

heat flow in a heat flow province:

$q^{*} \cong 0.6 \bar{q}_{0}$

Simply stated, within a continental region with mean heat flow $\bar{q}_{0}$, approximately 0.4 of the mean flux arises from near-surface radiogenic sources, and 0.6 comes from greater depths. This empirical partition of $\bar{q}_{0}$ thus fixes the contribution of the enriched zone

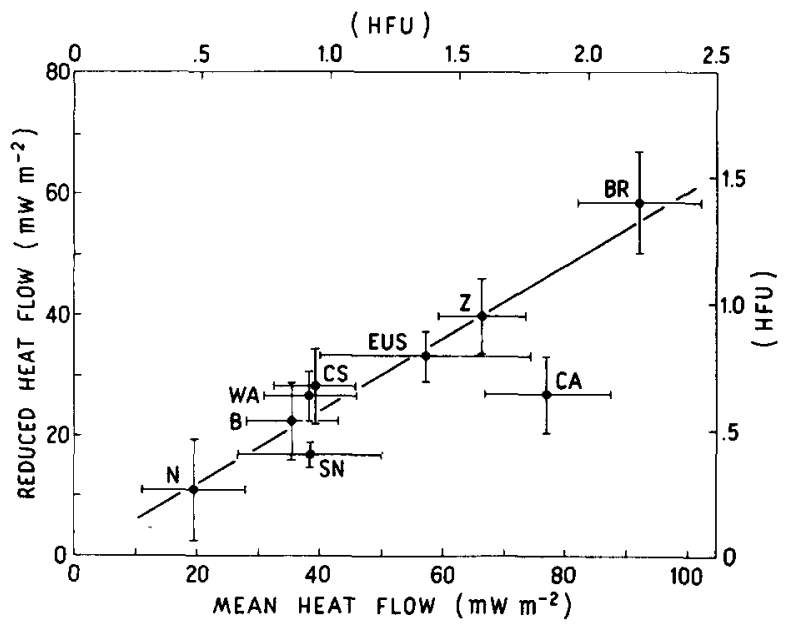

Fig. 3. Reduced heat flow versus mean heat flow in several heat flow provinces. Horizontal bars represent standard deviation about the mean heat flow; vertical bars represent uncertainty of estimate of reduced heat flow. Regions represented: $\mathrm{N}=$ Niger, $\mathrm{B}=$ Baltic shield, $\mathrm{SN}=$ Sierra Nevada, $\mathrm{WA}=$ western Australia, $\mathrm{CS}=$ Canadian shield, $\mathrm{EUS}=$ eastern United States, $\mathrm{Z}=\mathrm{Zambia}, \mathrm{CA}=$ central Australia, $\mathrm{BR}=$ Basin and Range. at $b \bar{A}_{0}=0.4 \bar{q}_{0}$ which, if $b$ is known or assumed, yields the mean surface heat production of the enriched zone.

With the necessary parameters of the crustal heat source distribution determinable from the above arguments, mantle heat flow for continental areas can now be calculated from equation (1). For the computation in each $5^{\circ} \times 5^{\circ}$ element we adopt the following numerical values:

$q_{0}=\bar{q}_{0}$, the mean $5^{\circ} \times 5^{\circ}$ surface heat flow

$A_{0}=\left(\bar{q}_{0}-q^{*}\right) / b$ wherever $q^{*}$ and $b$ are known from measurements, otherwise

$A_{0}=0.4 \bar{q}_{0} / b$, with $q^{*}=0.6 \bar{q}_{0}$ and $b=8.5 \mathrm{~km}$ assumed

$A_{1}=0.21 \mu \mathrm{W} \mathrm{m}^{-3}$

$z_{\mathrm{m}}=40 \mathrm{~km}$

We recognize that variations in crustal thickness exist; a range of $\pm 10 \mathrm{~km}$ about the adopted value of $40 \mathrm{~km}$ embraces nearly all reported continental values As the effect of this variation on heat flow is only \pm 2 $\mathrm{mW} \mathrm{m} \mathrm{m}^{-2}$ we have elected to omit it in the present analysis.

\subsection{Oceans}

The principal characteristic of the thermal regime of the oceanic lithosphere is its transient cooling following formation at a spreading ridge. In pioneering calculations, McKenzie [15] and Sclater and Francheteau [16] showed that the variations of heat 
flow and topography away from a spreading ridge are reasonably explained by the cooling and contraction of a slab of uniform thickness and with isothermal lower boundary. Subsequent calculations by several workers [17-19] have retained the fundamental concept of a cooling slab but have relaxed the constraint of uniform thickness. These models have in common a thermal definition for the base of the slab, i.e. the depth at which the actual temperature reaches some constant value, or some specified fraction of the solidus temperature.

The basis of our oceanic geotherms is the error function solution for the one-dimensional cooling of a semi-infinite medium with an initial linear temperature gradient, $T(z, t)=T_{0} \operatorname{erf}\left(z^{2} / 4 \alpha t\right)^{1 / 2}+c z$. Sclater et al. [20] criticize the use of the simple error function solution by Davis and Lister [18] because it fails to yield heat flow adequate to match the observations in the older regions of the oceans, data which Sclater et al. [20] believe are the only measurements that are quantitatively reliable. We surmount that criticism in part by including in the initial condition the linear gradient, and by including a $6.5-\mathrm{km}$ crustal layer with a heat production characteristic of basalt. The initial gradient and heat production together contribute a steady $10 \mathrm{~mW} \mathrm{~m}^{-2}$, or almost a quarter of the heat flow in the old oceans. It is this extra increment to the error function solution that enables the old ocean heat flow constraint to be met.

In our oceanic model the mantle heat flow $q_{\mathrm{m}}$ is evaluated from:

$q_{\mathbf{m}}=\left.K \frac{\partial T}{\partial z}\right|_{z=z_{\mathbf{m}}}=\frac{K T_{0}}{\sqrt{\pi \alpha t}} \exp \left(-z_{\mathrm{m}}^{2} / 4 \alpha t\right)+K c$

where $K$ is thermal conductivity, $T_{0}$ is the initial surface temperature, $c$ the initial temperature gradient, $z_{\mathrm{m}}$ the depth to the mantle, $\alpha$ the thermal diffusivity, and $t$ is time after the initiation of cooling. The time is determinable from the fact that a given surface heat flow occurs at a specific time in the cooling history:

$q_{0}=\left.K \frac{\partial T}{\partial z}\right|_{z=0}=\frac{K T_{0}}{\sqrt{\pi \alpha t}}+A h+K c$

or:

$\sqrt{t}-\frac{K T_{0}}{\sqrt{\pi \alpha}\left(q_{0}-A h-K c\right)}$ where $A$ and $h$ are oceanic crust heat production and thickness, respectively. Thus in a $5^{\circ} \times 5^{\circ}$ oceanic element with surface heat flow $q_{0}$ and age $t$, the mantle heat flow is given by:

$q_{\mathrm{m}}-\left(q_{0}-A h-K c\right) \exp \left(-z_{\mathrm{m}}^{2} / 4 \alpha t\right)+K c$

For the calculations, the following values were used:

$$
\begin{aligned}
q_{0} & =\bar{q}_{0}, \text { the mean } 5^{\circ} \times 5^{\circ} \text { surface heat flow } \\
K & =3.1 \mathrm{~W} \mathrm{~m}^{-1} \mathrm{~K}^{-1} \\
\alpha & =7.5 \times 10^{-7} \mathrm{~m}^{2} \mathrm{~s}^{-1} \\
T_{0} & =1200^{\circ} \mathrm{C} \\
c & =2.25 \mathrm{~K} \mathrm{~km}^{-1} \\
A & =0.5 \mu \mathrm{W} \mathrm{m}-3 \\
h & =z_{\mathrm{m}}=6.5 \mathrm{~km}
\end{aligned}
$$

As with the continental case, variations in oceanic crustal thickness introduce only small variations in $q_{\mathrm{m}}$ and can be safely ignored.

\section{Spherical harmonic analysis of mantle heat flow}

A main concern in this study is to determine the relationships, if any, that exist between broad long wavelength variations of the heat flow field and other global geophysical data sets. It is convenient therefore to express the fields in terms of surface spherical harmonic functions. At the same time it should be realized that any field reconstructed from the harmonic coefficients contains an amount of smoothing characteristic of the harmonic degree to which the field is expressed. For example, in a 12 th degree reconstruction features with half-wavelengths less than about $1500 \mathrm{~km}$ will be suppressed.

The mantle heat flow data set subjected to analysis comprises values, computed by equations (1) and (2), for all $5^{\circ} \times 5^{\circ}$ elements on the surface of the globe. The data set has been represented by a spherical harmonic expansion of the form:

$$
\begin{aligned}
& q_{\mathrm{m}}(\theta, \phi)=\sum_{n=0}^{N} \sum_{m=0}^{n}\left[A_{n m} \cos (m \phi)+B_{n m} \sin (m \phi)\right] \\
& \times P_{n m}(\cos \theta)
\end{aligned}
$$

where $q_{\mathrm{m}}$ is the mantle heat flow field, $\theta$ is colatitude, $\phi$ is longitude, $A_{n m}$ and $B_{n m}$ the coefficients of the ex. pansion, and $P_{n m}$ the associated Lengendre functions 
fully normalized so that

$$
\int_{0}^{2 \pi} \int_{0}^{\pi}\left[P_{n m}(\cos \theta) \cos (m \phi)\right]^{2} \sin \theta \mathrm{d} \theta \mathrm{d} \phi=4 \pi
$$

The spherical harmonic coefficients $A_{n m}$ and $B_{n m}$ up to degree $n=18$ were calculated by numerical integration from:

$B_{n m}=\frac{1}{4 \pi} \int_{0}^{2 \pi} \int_{0}^{\pi} q_{m}(\theta, \phi) \underset{\sin (m \phi)}{\cos (m \phi)} P_{n m}(\cos \theta) \sin \theta \mathrm{d} \theta \mathrm{d} \phi$

and are given through degree 12 in Table 2 . The global mean value for mantle heat flow is $48 \mathrm{~mW} \mathrm{~m}^{-2}$, compared to the mean surface heat flow of $59 \mathrm{~mW} \mathrm{~m}^{-2}$.
Fig. 4 shows the contoured degree 12 spherical harmonic reconstruction of mantle heat flow.

There are two important differences between the mantle heat flow (Fig. 4) and the surface heat flow (Fig. 1). First, the mantle heat flow pattern shows a contrast between continents and oceans which is not so evident in surface heat flow. The $40-\mathrm{mW} \mathrm{m}^{-2}$ contour of mantle heat flow is nearly everywhere circum. or intra-continental. The pattern of near equality in the mean continental and oceanic surface heat flow (continents, $53 \mathrm{~mW} \mathrm{~m}^{-2}$; oceans, $62 \mathrm{~mW} \mathrm{~m}^{-2}$ ) is altered to one of greater contrast in the mantle heat flow (continents, $28 \mathrm{~mW} \mathrm{~m}^{-2}$; oceans, $57 \mathrm{~mW} \mathrm{~m}^{-2}$ ). This contrast results from continental crust being both thicker and more radioactive than oceanic crust, and

TABLE 2

Fully normalized spherical harmonic coefficients of mantle heat flow through degree and order 12 , in units of $\mathrm{mW} \mathrm{m}^{-2}$

\begin{tabular}{|c|c|c|c|c|c|c|c|c|c|c|c|}
\hline$n$ & $m$ & $A_{n m}$ & $B_{n m}$ & $n$ & $m$ & $A_{n m}$ & $B_{n m}$ & $n$ & $m$ & $A_{n m}$ & $B_{n m}$ \\
\hline 0 & 0 & 48.305 & & 7 & 3 & 1.168 & -0.741 & 10 & 7 & -0.584 & 0.234 \\
\hline 1 & 0 & -4.991 & & 7 & 4 & 1.085 & -0.673 & 10 & 8 & -0.562 & 0.749 \\
\hline 1 & 1 & -4.580 & -3.300 & 7 & 5 & -0.582 & 1.208 & 10 & 9 & 0.128 & 0.855 \\
\hline 2 & 0 & -2.303 & & 7 & 6 & 0.100 & 0.777 & 10 & 10 & 0.012 & -0.484 \\
\hline 2 & 1 & -0.079 & -0.624 & 7 & 7 & 0.186 & 0.694 & 11 & 0 & -0.144 & \\
\hline 2 & 2 & -1.692 & 1.783 & 8 & 0 & 0.328 & & 11 & 1 & -1.131 & 0.863 \\
\hline 3 & 0 & 1.800 & & 8 & 1 & 0.098 & 1.806 & 11 & 2 & 0.208 & 0.005 \\
\hline 3 & 1 & 0.170 & -0.953 & 8 & 2 & 0.695 & 0.923 & 11 & 3 & 0.284 & 0.048 \\
\hline 3 & 2 & 2.358 & -2.868 & 8 & 3 & -0.049 & -0.071 & 11 & 4 & -0.015 & -0.165 \\
\hline 3 & 3 & 1.243 & -0.192 & 8 & 4 & -0.706 & -0.060 & 11 & 5 & -0.476 & 0.781 \\
\hline 4 & 0 & -2.694 & & 8 & 5 & 0.770 & 0.652 & 11 & 6 & 0.123 & -0.365 \\
\hline 4 & 1 & 1.274 & 0.831 & 8 & 6 & 0.430 & 1.074 & 11 & 7 & 0.165 & -0.002 \\
\hline 4 & 2 & 2.411 & 0.413 & 8 & 7 & -0.932 & -0.581 & 11 & 8 & 0.338 & 0.856 \\
\hline 4 & 3 & -1.117 & -1.063 & 8 & 8 & 0.321 & 0.039 & 11 & 9 & 0.115 & 1.169 \\
\hline 4 & 4 & 1.131 & -5.026 & 9 & 0 & 1.299 & & 11 & 10 & -0.264 & -0.645 \\
\hline 5 & 0 & 3.408 & & 9 & 1 & 1.528 & 0.206 & 11 & 11 & -0.268 & -0.777 \\
\hline 5 & 1 & -0.177 & 0.147 & 9 & 2 & 0.422 & -0.415 & 12 & 0 & 0.534 & \\
\hline 5 & 2 & 2.293 & 0.882 & 9 & 3 & -1.100 & -0.995 & 12 & 1 & -0.326 & -0.233 \\
\hline 5 & 3 & 1.257 & -0.930 & 9 & 4 & 0.281 & -0.965 & 12 & 2 & 0.176 & 0.498 \\
\hline 5 & 4 & -4.530 & 1.871 & 9 & 5 & 0.170 & -0.334 & 12 & 3 & 0.784 & 0.034 \\
\hline 5 & 5 & -1.245 & -2.269 & 9 & 6 & 0.654 & -0.063 & 12 & 4 & 0.478 & -0.371 \\
\hline 6 & 0 & -1.653 & & 9 & 7 & -0.096 & -0.705 & 12 & 5 & -0.142 & -0.504 \\
\hline 6 & 1 & 1.191 & 1.017 & 9 & 8 & 0.114 & 0.119 & 12 & 6 & 0.232 & -0.823 \\
\hline 6 & 2 & 1.988 & -1.513 & 9 & 9 & 1.036 & 1.747 & 12 & 7 & -0.437 & 0.546 \\
\hline 6 & 3 & -0.492 & -1.039 & 10 & 0 & 0.907 & & 12 & 8 & 0.495 & 1.199 \\
\hline 6 & 4 & -1.097 & -0.981 & 10 & 1 & 0.109 & -0.005 & 12 & 9 & -0.504 & 0.167 \\
\hline 6 & 5 & 0.626 & 0.825 & 10 & 2 & 0.573 & 0.498 & 12 & 10 & 0.707 & -0.562 \\
\hline 6 & 6 & 0.060 & 1.144 & 10 & 3 & 1.307 & 0.386 & 12 & 11 & -0.596 & -0.278 \\
\hline 7 & 0 & 1.273 & & 10 & 4 & -0.528 & 0.235 & 12 & 12 & 0.027 & 1.269 \\
\hline 7 & 1 & -0.382 & -1.424 & 10 & 5 & -0.237 & -0.154 & & & & \\
\hline 7 & 2 & -1.342 & 0.203 & 10 & 6 & -1.138 & 0.612 & & & & \\
\hline
\end{tabular}




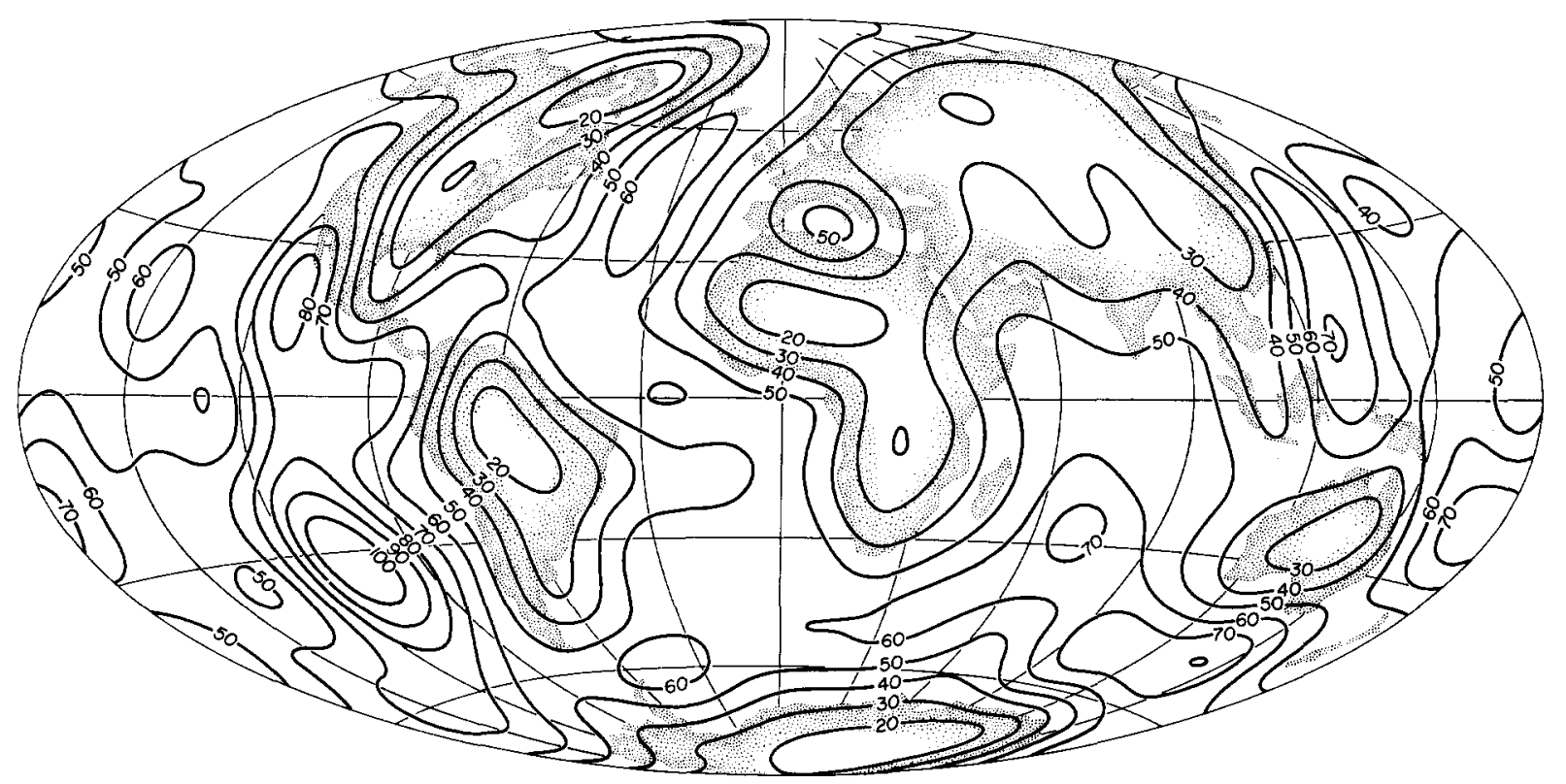

Fig. 4. Degree 12 spherical harmonic representation of mantle heat flow. Contours in $\mathrm{mW} \mathrm{m}^{-2}$.

thus a considerably lesser fraction of the surface heat flow remains after stripping of the continental crustal contribution.

The second difference relates to the diminished contrast in mantle heat flow within continental regions. The new empiricism that $q^{*}=0.6 \bar{q}_{0}$ implies that manthe heat flow variation under continents should be only $60 \%$ of the surface heat flow variation; the greater variation in the surface heat flow being attributed to regional differences in crustal radioactivity and/or depth of erosion. Australia, where considerable heat flow and heat production data are available [21] affords a useful example. Whereas the mean surface heat flow of $81 \mathrm{~mW} \mathrm{~m}^{-2}$ in the Proterozoic rocks of central Australia is double the characteristic value of $39 \mathrm{~mW} \mathrm{~m}^{-2}$ observed in the western Australian shield, both regions have essentially the same reduced heat flow of $27 \mathrm{~mW} \mathrm{~m}^{-2}$. This effect can be seen clearly in the spherical harmonic representations of surface and mantle heat flow (Figs. 1 and 4 ) in the vicinity of Australia. The surface heat flow contour pattern is complex, reflecting the strong regional variability of the surface flux, whereas the mantle heat flow contours are simple closed curves centered on the continent.

The r.m.s. variability of mantle heat flow calculated

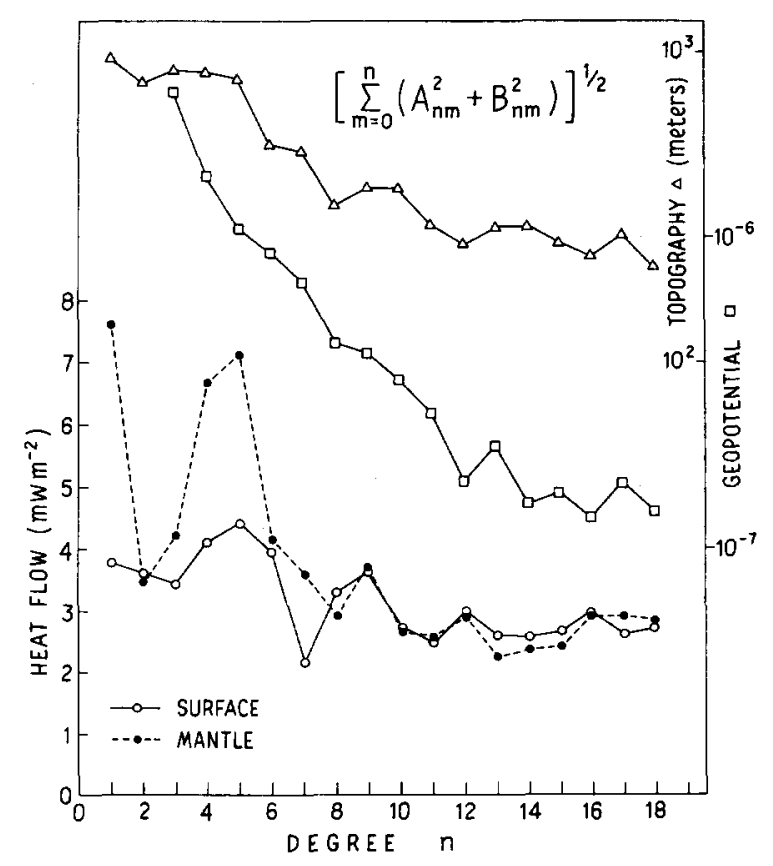

Fig. 5. Degree variance of surface heat flow, mantle heat flow, geopotential, and topography. 
from:

$\left[\sum_{m=0}^{n}\left(A_{n m}^{2}+B_{n m}^{2}\right)\right]^{1 / 2}$

is shown in Fig. 5, with the spectra of surface heat flow, geopotential, and topography included for comparison. The mantle heat flow spectrum has pronounced strength at degrees 1,4 and 5 which is not present in the surface heat flow. From degree 8 on, surface and mantle spectra closely resemble each other, and are nearly flat at about $2.5 \mathrm{~mW} \mathrm{~m}{ }^{-2}$ from degrees 10 to 18 . These peaks correspond to similar peaks in the continent-ocean function of Balmino et al. [22] and are consistent with the continent-ocean contrast in mantle heat flow already described.

\section{Correlation of heat flow with other geophysical data}

Correlation between data sets expressed in spherical harmonic expansions can be determined from the coefficients of the expansions. It is useful to compute both the overall correlation $r$, and the correlation as a function of wavelength, the degree correlation $r_{n}$, given respectively by:

$$
\begin{aligned}
& r=\frac{\sum_{n=1}^{N} \sum_{m=0}^{n}\left(A_{n m} A_{n m}^{\prime}+B_{n m} B_{n m}^{\prime}\right)}{\left[\sum_{n=1}^{N} \sum_{m=0}^{n}\left(A_{n m}^{2}+B_{n m}^{2}\right) \cdot \sum_{n=1}^{N} \sum_{m=0}^{n}\left(A_{n m}^{\prime 2}+B_{n m}^{\prime 2}\right)\right]^{1 / 2}} \\
& r_{n}=\frac{\sum_{m=0}^{n}\left(A_{n m} A_{n m}^{\prime}+B_{n m} B_{n m}^{\prime}\right)}{\left[\sum_{m=0}^{n}\left(A_{n m}^{2}+B_{n m}^{2}\right) \cdot \sum_{m=0}^{n}\left(A_{n m}^{\prime 2}+B_{n m}^{\prime 2}\right)\right]^{1 / 2}}
\end{aligned}
$$

where $A_{n m}, B_{n m}$, and $A_{n m}^{\prime}, B_{n m}^{\prime}$ are harmonic coefficients for two sets of $F$ and $F^{\prime}$. These definitions are the same as given by Kaula [23] and used by Toksoz et al. [24].

Although few geophysical fields have been mapped with sufficient coverage to permit determination of the higher harmonic coefficients, at least the relationships between surface and mantle heat flow, and each with the gravitational potential and topography may now be examined. The degree correlations of mantle heat flow with surface heat flow are shown in Table 3, and as might be expected all are positive and above 0.6 ; all but three are greater than 0.7 , and the overall correlation is 0.83 .

The gravitational potential of the earth is another field known in adequate detail to permit correlation with the heat flow. The low-degree harmonics of the geopotential have been known for more than a decade and the higher harmonics continue to be defined and refined. For the purposes of comparison with the heat flow field we use the GEM-8 earth model of Wagner et al. [25] which is a combination solution utilizing satellite data to determine the field com. pletely through degree and order 16 , and $5^{\circ} \times 5^{\circ}$ mean free-air anomalies from surface observations to extend the field completely to degree and order 25 .

The r.m.s. variability of the geopotential is shown in Fig. 5, and it is apparent that the regular diminution of strength out to degree 12 has little resemblance to the spectral distribution of mantle heat flow. The surface heat flow spectrum shows a general falloff from degrees 5 to 12 , although not as uniformly as the geopotential does. From degrees 12 to 18 each of the spectra flatten.

The degree correlations of surface and mantle heat flow with the geopotential are shown in Fig. 6, from degrees 3 to 18 . Both surface and mantle heat flow show a predominant positive correlation with the geopotential, but at nearly every degree the mantle heat flow correlation is less positive, suggesting that some of the heterogeneity that contributes to the broad geographic variations in the gravity field may

\section{TABLE 3}

Degree correlations of surface heat flow with mantle heat flow

\begin{tabular}{llll}
\hline$n$ & $r_{n}$ & $n$ & $r_{n}$ \\
\hline 1 & 0.96 & 10 & 0.68 \\
2 & 0.66 & 11 & 0.85 \\
3 & 0.60 & 12 & 0.87 \\
4 & 0.95 & 13 & 0.89 \\
5 & 0.93 & 14 & 0.84 \\
6 & 0.89 & 15 & 0.88 \\
7 & 0.79 & 16 & 0.92 \\
8 & 0.81 & 17 & 0.87 \\
9 & 0.90 & 18 & 0.71 \\
\hline
\end{tabular}




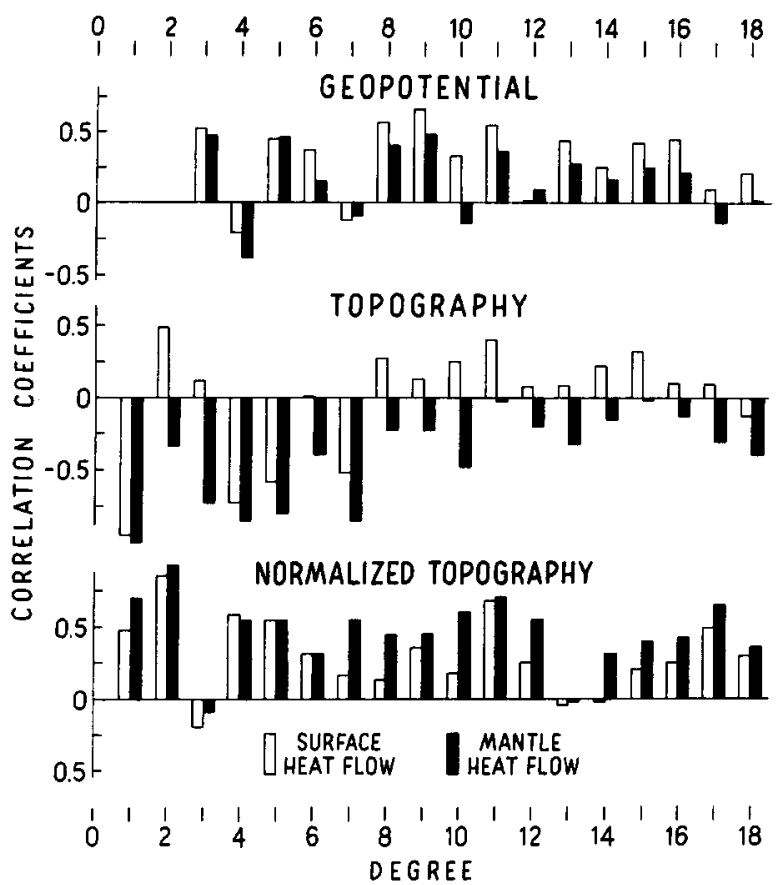

Fig. 6. Degree correlations of geopotential, topography, and normalized topography with surface and mantle heat flow.

lie within the crust and be of thermal origins. That the heat flow remains positively correlated, albeit less so, after deletion of the crustal contribution, is also suggestive that thermally related heterogeneity extends well into the mantle.

The positive correlation of heat flow with the geopotential is a result contrary to some earlier correlations based on low-degree harmonic analyses of very sparse heat flow data sets $[26,27]$, but similar to the result of Toksoz et al. [24]. The positive correlation is consistent with the numerical deductions of McKenzie et al. [28] that positive free-air gravity anomalies should exist over the ascending limb of a convection cell, although we by no means wish to imply that all regions of above average heat flow delineate convective upwellings, nor that there is in general a one-to-one correspondence between patterns of convective circulation and heat flow.

The topography of the earth is also sufficiently well known to permit comparisons with the surface and mantle heat flow. For the purpose of correlations we utilize the spherical harmonic representation of the topography by Balmino et al. [22]. Significant correlations between heat flow and topography within both continents and oceans are not unexpected. In the oceans the principal topographic features, the midocean rises, are generally interpreted to be newly formed and thermally expanded lithosphere, which contracts as it cools moving away from a spreading ridge, thus forming the slope of the oceanic rise. Similar but less obvious arguments can be made with respect to continental morphology, based on the fact that the shields and platforms with below average heat flow generally comprise the widespread low-lying areas of the continents. However, the first-order topography on the earth, i.e. the continents and oceans themselves, is not of thermal origin.

The overall correlations of the topography (the solid surface of the earth measured from sea level) with surface and mantle heat flow are -0.18 and -0.64 , respectively, the negative correlations indicating principally that the oceanic regions generally lie below the global mean elevation $(-2300 \mathrm{~m})$ and exhibit above average surface and mantle heat flow. The individual degree correlations (Fig. 6) show the mantle heat flow to be more negatively correlated with topography at every degree than is the surface flow; moreover the mantle heat flow correlation at every degree is absolutely negative. The elimination of positive correlation of topography with the mantle heat flow at any degree arises from the more substantial decrease of heat flow from surface to mantle on the continents (positive topography) than in the oceans (negative topography). The emergent pattern of mantle heat flow, with the readily apparent contrast between continents and oceans (Fig. 4), is sufficiently strong to yield a negative correlation at every degree of the spectrum.

However, the negative correlation of topography with surface and particularly mantle heat flow is misleading because it obscures the basic positive correlation that exists between heat flow and topograghy in the oceans, as expressed by the oceanic risecooling lithosphere system. The obfuscation occurs because the first-order topography of the earth, the continents and oceans, arises fundamentally from a petrological, and not thermal, difference between the two elements. Isostatic considerations argue that the lower-density continents should stand about $5 \mathrm{~km}$ higher than the denser oceans. Topography of thermal origin, in both oceans and continents, may be super- 
posed upon the respective base levels in each region. For a positive correlation between heat flow and topography to be apparent, the base line differences between continents and oceans must be removed, i.e. the topography must be "normalized" to remove the petrologic contrast between continents and oceans. To illustrate this effect we have performed an extremely simple normalization, consisting of adding $5.5 \mathrm{~km}$ to all oceanic depths, an amount adequate to bring typical old and deep ocean basins with low heat flow up to an equivalent level with the old low heat flow continental shields, effectively eliminating the base line difference between continents and oceans. This new "normalized" topography was then subjected to harmonic analysis, and correlated with heat flow. The degree correlations are shown in Fig. 6, and show a general positive correlation of heat flow and normalized topography at nearly every degree, a reversal from the negative correlations of heat flow with actual topography. We believe that the process of "normalization" has effectively served as a filter which separates thermal from petrological effects in the topography and emphasizes the significant role that temperature plays in the morphology of both continents and oceans.

\section{Geodynamic implications of mantle heat flow}

The principal result to emerge from the mapping of mantle heat flow is the demonstration that the heat flux in the upper mantle beneath continents is significantly less than beneath oceans. This in turn implies that substantial temperature differences are likely to exist in the upper mantle, perhaps as great as $400^{\circ} \mathrm{C}$ at a depth of $100 \mathrm{~km}$ between shields and young ocean floor. The suggestion of such temperature differences is not new; both MacDonald [29] and Clark and Ringwood [30] calculated "representative" continental and oceanic geotherms, based on geochemical models, which yielded temperature differences greater than $200^{\circ} \mathrm{C}$ well within the upper mantle. Moreover, seismological observations now indicate differences in the velocity structure beneath stable shields, tectonic regions, and ocean basins, differences

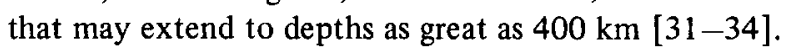
The velocities generally vary inversely with heat flow, and the magnitude of the variations can be adequately accounted for by the temperature dependence of velocity of characteristic mantle materials.

The implications of this variable thermal structure for geodynamic models are numerous, deriving from the fact that many mechanical properties such as viscosity and rigidity are strongly temperature dependent. Indeed, the thickness and durability of the lithosphere, and the sub-lithosphere viscosity must certainly show regional variability governed by the thermal condition, with attendant consequences for asthenospheric circulation, plate velocities and tectonic regimes. While the development of these topics is beyond the scope of this paper, the interested reader can find a cogent and stimulating discussion of the geodynamic aspects of deep thermal structure in a recent paper by Jordan [35].

\section{Acknowledgements}

This research was partially supported by the U.S. National Science Foundation, Earth Science section, under Grant DES-7517065.

\section{References}

1 D.S. Chapman and H.N. Pollack, Global heat flow: a new look, Earth Planet. Sci. Lett. 28 (1975) 23-32.

2 F. Birch, R.F. Roy and E.R. Decker, Heat flow and thermal history in New York and New England, in: Studies of Appalachian Geology: Northern and Maritime, E. Zen, W.S. White, J.B. Hadley and J.B. Thompson, Jr., eds. (Interscience, New York, N.Y.) 437-451.

3 A.H. Lachenbruch, Crustal temperature and heat production: implications of the linear heat-flow relation, J. Geophys. Res. 75 (1970) 3291 -3300.

4 C.A. Swanberg, Vertical distribution of heat generation in the Idaho batholith, J. Geophys. Res. 77 (1972) $2508-2513$.

5 C.J. Hawkesworth, Vertical distribution of heat production in the basement of the eastern Alps, Nature 249 (1974) 435.

6 R.D. Hyndman, I.B. Lambert, K.S. Heier, J.C. Jaeger and A.E. Ringwood, Heat flow and surface radioactivity measurenients in the Precambrian shield of western Austrọlia, Phys. Earth Planet. Inter. 1 (1968) 129-135.

7 S.B. Smithson and E.R. Decker, A continental crustal model and its geothermal implications, Earth Planet. Sci. Lett. 22 (1974) 215-225.

8 R.F. Roy, D.D. Blackwell and F. Birch, Heat generation of plutonic rocks and continental heat-flow provinces, 
Earth Planet. Sci. Lett. 5 (1968) 1-12.

9 J.H. Sass, A.H. Lachenbruch, R.J. Munroe, G.W. Greene and and T.H. Moses, Jr., Heat flow in the western United States, J. Geophys. Res. 65 (1971) 6376-6413.

10 J.H. Sass and R.J. Munroe, Basic heat flow data from the United States, U.S. Geol. Surv., Menlo Park, Calif., Open File Rep. 74-79 (1974).

11 J.C. Jaeger, Heat flow and radioactivity in Australia, Earth Planet. Sci. Lett. 8 (1970) 285-292.

12 D.S. Chapman and H.N. Pollack, Heat flow and incipient rifting in Central Africa, Nature 256 (1975) 28-30.

13 R.V.M. Rao and A.M. Jessop, A comparison of the thermal characters of shields, Can. J. Earth Sci. 12 (1975) 347-360.

14 D.S. Chapman and H.N. Pollack, Cold spot in West Africa: anchoring the African plate, Nature 250 (1974) 477-478.

15 D.P. McKenzie, Some remarks on heat flow and gravity anomalies, J. Geophys. Res. 72 (1967) 6261-6273.

16 J.F. Sclater and J. Francheteau, The implications of terrestrial heat flow observations on current tectonic and geochemical models of the crust and upper mantle of the earth, Geophys. J. R. Astron. Soc. 20 (1970) 509-542.

17 R.L. Parker and D.W. Oldenburg, Thermal model of ocean ridges, Nat. Phys. Sci. 242 (1973) 137-139.

18 E.E. Davis and C.R.B. Lister, Fundamentals of ridge crest topography, Earth Planet. Sci. Lett. 21 (1974) 405-413.

19 S.T. Crough, Thermal model of oceanic lithosphere, Nature 256 (1975) 388-390.

20 J.G. Sclater, L.A. Lawver and B. Parsons, Comparison of long-wave length residual elevation and free-air gravity anomalies in the North Atlantic and possible implications for the thickness of the lithospheric plate, J. Geophys. Res. 80 (1975) 1031-1052.

21 J.H. Sass, J.C. Jaeger and R.J. Munroe, Heat flow and near-surface radioactivity in the Australian continental crust, U.S. Geol. Surv., Menlo Park, Calif., Open File Rep. 76-250 (1976).

22 G. Balmino, K. Lambeck and W.M. Kaula, A spherical harmonic analysis of the earth's topography, J. Geophys. Res. 78 (1973) 478-481.
23 W.M. Kaula, Geophysical implications of satellite determinations of the earth's gravitational field, Space Sci. Rev. 7 (1967) 769-794.

24 M.N. Toksoz, J. Arkani-Hamed and C. Knight, Geophysical data and long-wave heterogeneities of the earth's mantle, J. Geophys. Res. 74 (1969) 3751-3770.

25 C.A. Wagner, F.J. Lerch, J.E. Brownd and J.A. Richardson: Improvement in the geopotential derived from satellite and surface data (GEM-7 and GEM-8), Goddard Space Flight Center, Greenbelt, Md., Doc. X-921076-20 (1976) 11 pp.

26 C.Y. Wang, Some geophysical implications from gravity and heat flow data, J. Geophys. Res. 70 (1965) 56295634.

27 M.N. Toksoz and J. Arkani-Hamed, Seismic delay times: correlation with other data, Science 158 (1967) 783785.

28 D.P. McKenzie, J.M. Roberts and N.O. Weiss, Convection in the earth's mantle: towards a numerical solution, J. Fluid Mech. 62 (1974) 465-538.

29 G.J.F. MacDonald, The deep structure of continents, Rev. Geophys. Space Phys. 1 (1963) 587-665.

30 S.P. Clark and A.E. Ringwood, Density distribution and constitution of the mantle, Rev. Geophys. Space Phys. 2 (1964) 35-88.

31 A.R. Leeds, L. Knopoff and E.G. Kausel, Variations of upper mantle structure under the Pacific Ocean, Science 186 (1974) $141-143$.

32 S.S. Alexander, Comparison of crust and mantle structure beneath shields and the influence of shield on the dynamics of plate motions, EOS Trans. Am. Geophys. Union, 55 (1974) 358-359.

33 N.N. Biswas and L. Knopoff, The structure of the upper mantle under the United States from the dispersion of Rayleigh waves, Geophys. J.R. Astron. Soc. 36 (1974) 515-539.

34 S.A. Sipkin and T.H. Jordan, Lateral heterogeneity in the upper mantle determined from the travel time of ScS, J. Geophys. Res. 80 (1975) 1474-1484.

35 T.H. Jordan, The continental tectosphere, Rev. Geophys. Space Phys. 13 (1975) 1-12. 